\title{
The Status Quo and Issues of Institutional Research in Japanese Universities - IR Offices at a Crossroads in Universities without Regular University Management
}

\author{
Miho Funamori *
}

\begin{abstract}
This paper examines the status quo and issues of institutional research (IR) in Japanese universities. There has been a big push from the government towards establishing IR offices to reinforce the governance of the university. There are now quite a few IR offices. However, they are reported to be on very unstable grounds.

This paper compares the US and Japanese IR offices by its mission, reporting line, and its services. It concludes that Japanese IR offices fail to establish the link to the decision-maker at the highest rank. It emphasizes that the absence of regular university management is inherently the cause of this malfunction. It proposes administrators and IR offices to work together to establish regular university management. It suggests providing IR offices a more stable ground and trust for regular university management to settle in.
\end{abstract}

Keywords: administration, evidence-based decision-making, institutional research, university management.

\section{Introduction}

The importance of evidence-based decision-making has gained ground globally. The world recession has called for rational management and greater accountability. Higher Education is no exception. Research activities are traditionally based on evidence, but now, the university management, and even teaching and learning are calling for evidence.

The purported massification of higher education is one of the main causes for this demand [1]. The shift towards knowledge-based economy led to greater university enrollment rate around $40-80 \%$, and higher education became a commodity for the mass population. In the time when only a few elites participated in higher education, universities were able to govern themselves by their own rules. However, in an age where a few ten-thousands enter a single university, and where universities have greater contact with the society through university-industry linkages and adult student enrollment, universities need to increase the transparency of their activities, and be accountable toward the society. These days, the society's regard toward universities as agents of economic change has also created a greater impact on the role of higher education.

\footnotetext{
* The University of Tokyo, Tokyo, Japan
} 
Concurrent with the issues of the massification of higher education, the financial stringency at higher education sector is also a great reason why evidence-based university management is needed. The global financial crises after the bankruptcy of Lehman Brothers directly affected the public funding towards higher education. The current fundamental background involves the public funds not being able to sustain the massification of higher education. Hitherto, universities were required to do more with less funding which drove universities to improve their operations by introducing rational university management. The deficit in funding also resulted in the introduction or increase of tuition, which caused students to become more cost-conscious, and to start searching for universities with the "Value for Money" programs and courses.

Greater enrollment also led to greater diversity in academic rigor and motivation in universities among students. Uniformed teaching became ineffective, and universities needed to provide student support based on individual student's need. Since the student body was too large for the university staff to become familiar with, student data on their academic performance and family backgrounds were needed to provide individualized care. In some advanced cases, electronic systems that automatically provide personalized advice to students are developed using technologies such as learning analytics.

The US universities, which faced university enrollment rate above fifty percent before others, had established institutional research (IR) offices since the 1950s to equip their university management with sufficient and relevant data. In the beginning, the IR offices produced only university fact books with some basic data. However, with the rise of student activism and economic recession during the 1960-80s, they have gradually adapted also the role of university planning and strategic analysis [2].

Universities in other parts of the world started to work on university reform since the 1990s. The need for strategic university management arose as part of university reform. Until then, European universities were in general regarded as a social good where tuition was free, and managing universities was regarded as ludicrous. The university enrollment also did not rise as fast as in the US. It was just after the 1980s when Margaret Thatcher introduced the idea of new public management and neo-liberalism, which was also propagated into the higher education sector. Since then, world universities began to question about the agile and strategic university management.

Japanese universities have also been experiencing comprehensive university reforms in a large scale since the 1990s. It was at that time when the university enrollment population started to shrink, the economic bubble collapsed, and the impact of globalization became apparent. Japanese national universities became corporatized in 2004. Since then, the public funding shrank by one percent every year. Japanese private universities are facing tough times because of the shrinking population. More than forty percent of private universities are not able to fill their student quota since 2006 [3]. Moreover, since 2009, there is more space available than applicants for admission. This means that there are more and more students enrolled who have no great intention to learn, which forces universities to provide great student support to graduate these students.

The Ministry of Education, Culture, Sports, Science and Technology (MEXT) proposed the idea that establishing IR office would help to implement rational university management to cope with the financial crisis and the impact of massification of higher education. The report "Towards Establishing Bachelor's Degree Program" in 2008 by the Central Council for Education (Chuou Kyouiku Shingikai) mentions the need for IR offices [4]. Since then, IR offices and IR staff have been gradually established in Japanese universities. After 2014, when it was made clear by MEXT that the existence of IR offices would work positively in acquiring funds from MEXT for private universities (Shigaku Jyosei), the number of IR offices in Japanese universi- 
ties started to grow rapidly. The statement in the note for preparing the Third Term Mid-term Objectives of the National University Corporations that national universities should consider establishing IR offices for greater efficiency and effectiveness in university management also contributed to an increase in IR offices [5].

Even though there are more and more IR offices being established, there are only a few cases where the IR offices are reported to have worked effectively. IR seminars are filled with new IR staff members who do not have any idea what to do at their university. Even IR staff members who have already had several years work-experience are anxious that the administrators do not care what is being worked out at their IR offices. There are also universities that have decided to shut down their IR office and let individual administrative departments perform the function in their respective fields. There are also cases where IR offices, which became well-known in Japan for their success, were shut down after the change in the president and the administration.

What could be the cause of malfunction of IR offices in Japanese universities? This paper examines the status quo and issues of Japanese IR offices by comparing them with the IR offices in the US. It analyzes to what point Japanese IR offices fail to function effectively and discusses the future steps of IR offices.

\section{Analysis of Japanese IR offices}

The status quo of Japanese IR offices is analyzed by comparing Japanese and US IR offices by their mission, reporting line, and their service. The data on the activities of IR offices of respective countries are derived from academic articles and various survey reports on IR offices.

\subsection{How is the mission of IR offices defined?}

First, we compare Japanese and US IR offices by their mission.

The mission and activities of IR offices are said to vary greatly between different universities depending on the culture, tradition, and type of the respective universities. There have been several approaches in defining the mission of institutional research. Some define institutional research from its purpose [6], some from its function [7][8], its mission [9], the services it provides[10][11], the role of institutional researchers [12], and the size and staffing of institutional research offices[13]. However, the most simple and widely accepted definition is the one proposed by the Association for Institutional Research: "Institutional research is research conducted within an institution of higher education to provide information which supports institutional planning, policy formation and decision making" [14]. This means it is fundamental for institutional research to lead in the decision-making of the university administration either through support for assessment, planning, policy formation, or decision-making itself. Therefore, it is critical that institutional research be integrated into the university decision-making process [15][16], and that institutional researchers are closely linked with university administrators [17]. Some US university administrators deem IR offices necessary in making a decision.

On the contrary, Japanese institutional research offices lack the functions of supporting policy formation and decision-making in general. According to a survey in 2013 by MEXT, $69.1 \%$ of universities stated that they do not have any IR offices. Even for those universities that started to have an IR office, they identified their missions such as "monitoring educational reform" $(66.0 \%)$ and "accreditation purpose" $(62.2 \%)$ in the first place as reasons to establish IR offices at their university. The proactive purpose such as "support function for university management" 
(57.1\%) comes in the third place [18]. The situation is even worse in previous studies. A study performed in 2009 on private universities shows that $72.7 \%$ of all institutional research offices cover data management and data providing functions, but only $50.5 \%$ perform data analysis, and only $45.4 \%$ support planning of university reform based on data analysis [19]. An analysis in 2007 of three Japanese national universities based on the classification of IR functions by Thorpe concludes that none of the three offices supported decision-making or policy formation [9][20].

\subsection{To whom do the IR offices serve?}

As Delaney states, "Administrators play a critical role in enabling institutional researchers to produce successful studies" [17]. It is necessary to ensure that IR offices report to the decision maker of the highest rank. Taylor stresses that, "Placing the research office under an assistant vice-president weakens the institution's ability to make considered judgments using valid and reliable information" [21]. Presley indicates that, "Offices must be placed high enough in the organizational structure for the staff to be aware of the major issues and decisions facing senior management" [22]. Billups and DeLucia suggest that researchers of institutional research offices observe carefully where decision-making is taking place and where their audience is, in order to be integrated into organizational goals, and be able to become effective in university decision-making [16].

The IR offices in the US, in most cases, report to the president or the provost, i.e., to the decision makers of the highest rank. A study shows that $38 \%$ of institutional research offices in the United States are located under "academic affairs/provost," $26 \%$ under the "president/chancellor," $8 \%$ under "business affairs/services," $5 \%$ under "development/alumni," $4 \%$ under "student affairs/services," and 18\% under other units [23].

On the contrary, $25.2 \%$ of Japanese IR offices report to the "vice president," $23.9 \%$ report to the "director of the IR office," and the "president" comes in the third place with $17.6 \%$, followed by the "executive vice president" with $11.3 \%$ in the 2013 survey [18]. Japanese universities distinguish clearly the roles of the "vice president" and the "executive vice president," where the latter is the decision-maker by law. This means that most of the IR offices in Japan do not report to administrators of the highest rank. Even in cases where IR offices report to the "executive vice president" or to the "president," IR offices encounter difficulties as these administrators of the highest rank are occupied with too many tasks to such a degree that they cannot examine the analysis of IR offices carefully.

\subsection{What services do IR offices provide?}

Volkwein suggests classifying the functions of institutional research offices by their customers: (1) academic affairs support reporting to the provost, (2) business/finance support reporting to the chief financial officer, (3) enrollment management working with financial aid and admissions offices, and (4) student affairs support working with student affairs offices [24]. Here, whether and where these functions take place in Japanese universities are examined, based on Volkwein's classification.

\section{1) Academic affairs support}

This includes analyses of faculty workload, salaries, faculty publications, citations, honors, awards, services, student evaluation of instruction, and compilation of indicators of their quality and effectiveness.

US universities, especially the research universities, take the faculty recruitment and retention 
very seriously to maintain and improve their competitiveness. Therefore, US research universities have a vice provost for academic affairs in charge of faculty recruitment, or a provost who oversees the matter by him/herself. It is not just a formal process. These administrators examine the faculty matters carefully by themselves. They also chair the faculty selection committee held at the central administration level in most cases. The service of IR offices is to provide data and analysis to enable the faculty recruitment decision.

On the other hand, the faculty recruitment in Japanese universities takes place at each department and not through the central administration. The president appoints the faculty members as a matter of formality, but presidents or other administrators of highest rank usually do not have any say in the faculty selection. Since the faculty recruitment and the faculty evaluation do not take place in the central administration, academic affairs are usually not covered by the administration or the IR offices. In recent years, some universities have introduced faculty evaluation in response to the pressure from MEXT. Even in these cases, the faculty evaluation is usually used just as a reference to determine the allocation of bonus. They are not proactively used to raise the competitiveness of the university. If the IR office also covers academic affairs, it is just to prepare and update the researcher database that is open to the public on the university web page.

\section{2) Business/finance support}

This includes performing revenue projections, tuition pricing studies, fundraising analysis, the setting of resource allocation criteria, and compilation of indicators of productivity, efficiency, and cost.

In Japanese private universities, the business operations and finance management are the responsibility of their governing body called a "Gakkou-Houjin." The idea of "Gakkou-Houjin" is similar to the presidential administration of US universities. The administration by the provost dealing with inner university management would be the university administration unit in Japanese private university. The "Gakkou-Houjin" is running the private universities where business and financial operations are tangible. However, even they are not experienced in university management as they have been experiencing booming economy until the beginning of the 1990s. On top of this, the conflict between the "Gakkou-Houjin" and the university, seen in many private universities, makes it difficult for "Gakkou-Houjin" to convey their will to the university.

As for national universities, financial issues are usually managed by the executive vice president of finance and by the finance division. Their main mission is to oversee the financial situation of the university, and manage cost savings to correspond to the one percent cut in public funding every year. Tuition pricing studies and fundraising analysis are not carried out much since there is little freedom to make changes in these areas. Considering budgetary allocation across department is also less common, as student and faculty numbers are mostly fixed by departments.

\section{3) Enrollment management}

This includes performing enrollment projections, admissions marketing studies, retention and graduation estimates, alumni studies, and financial aid analysis.

Many of the US universities perform the enrollment management alongside financial management. Since US universities offer various ranks of fellowships to students, which affect the university finance directly, careful considerations for the enrollment and fellowships are made at the highest level. Enrollment management is also a vital issue for Japanese private universities, and the admission office, which handles the student forecast and student quota management, is 
ranked at a higher level compared to other administrative units. In some cases, they are even headed by the president him/herself. With the diversifying admission process in Japanese universities, the analysis at the admission office is more complex than ever.

In the case of national universities, enrollment management is less common than their private peers. Generally, national universities are placed higher than private universities, with less tuition and lower competition in student recruitment. They also lack freedom in setting tuition fees or student numbers.

\section{4) Student Affairs support}

This includes conducting student satisfaction surveys, management of the quality of residential life, analysis of diversity and the campus environment, and research of athletics performance.

Most Japanese universities conduct student satisfaction surveys in some form. Managing the quality of students' residential life has been a student affairs issue for some time. Emphasis on diversity and athletics are unique to US universities and does not apply to Japanese universities.

It can be said that student affairs support is carried out both at the private and national Japanese universities. However, it should also be added that they are not necessarily linked to high-level university decision-making.

Analysis 1 to 4 is summarized in Table 1. It can be said that national universities do not provide any institutional research services, whereas private universities do conduct institutional research to a certain degree that is directly linked to university decision-making.

Table 1: Institutional Research Services Performed in Japanese Universities

\begin{tabular}{|l|c|c|}
\hline \multicolumn{1}{|c|}{ Services of IR offices } & National University & Private University \\
\hline 1) Academic Affairs support & - & - \\
\hline 2) Business/Finance support & - & $\begin{array}{c}\text { "Gakkou-Houjin" } \\
\text { (governing body) }\end{array}$ \\
\hline 3) Enrollment management & (Admissions Office) & Admissions Office \\
\hline 4) Student Affairs support & \multicolumn{2}{|c|}{$\begin{array}{c}\text { (Student Affairs Section, } \\
\text { Center for Teaching and Learning) }\end{array}$} \\
\hline
\end{tabular}

a. Names in the table denote the offices in charge of the respective institutional research function.

b. Brackets denote services not necessarily linked to university decision-making but rather performed as routine procedural work.

\section{Discussion}

\subsection{Why do IR offices not function well in Japanese universities?}

Analysis on the mission and reporting line of IR offices shows that these units in Japanese universities are disconnected to the decision-making of the highest level. This means that IR offices in Japanese universities do not support the decision-making of the university even though it should be the key function of IR offices.

In fact, the main mission of IR offices at Japanese national universities, in most cases, is to 
prepare for the accreditation and university corporation evaluation to be eligible for public funding, whereas the main mission for IR offices at Japanese private universities is, in most cases, for student support [20][25]. In the former case, the IR office is set at central administration where their work is to serve the accountability issues towards the society and funding agencies, and not to contribute to the decision-making of their administrators who are leading the university reform. The administration also regards the IR office as such and does not demand policy formation or decision-making support. In the latter case, the IR function is carried out at units such as the center for teaching and learning which is a separate body to the central administration, and thus is only indirectly connected to the decision-making of the highest level. At the same time, since teaching and learning happen at academic units, the main work of IR offices, in this case, is to conduct student surveys. It is difficult to induce fundamental changes in teaching and learning by such surveys.

On the other hand, analysis of the services of IR offices indicates that university management in the field of academic affairs, business/finance support, and enrollment management are not carried out anywhere in Japanese universities, especially at national universities. If none of these regular university managements occur in the university, the IR offices should not be faulted if they could not function effectively in university decision-making. Rather, the lack of regular university management in Japanese universities is to be blamed for the weak administrative leadership in Japanese universities.

\subsection{Do we need IR offices in Japanese universities?}

If regular university management does not take place in Japanese universities, do we need IR offices at all? They do not have any working area where they could provide meaningful support.

The reason why regular university management is nonexistent at Japanese national universities lies in its history. National universities were part of MEXT's administrative unit before corporatization. Planning was performed at ministerial-level, and budget was allocated accordingly. Thus, there was no need at all for universities to manage their own university. After the corporatization in 2004, universities are required to self-manage. However, there is still very limited freedom in setting the tuition fees, student numbers for each department, the number of faculty members, their salary, and so forth. There are strict rules for investments, land sales, and establishing subsidiaries. Therefore, even after corporatization, there is only limited freedom in managing the university, which creates regular university management at national universities meaningless.

Nevertheless, public funding for national universities is cut by one percent every year, and the shrinking population and economic crisis are making the situation worse every year. This forces national universities to manage their university effectively in order to survive; it will also eventually lead to greater freedom in management. In fact, the Yamagata University, which is a national university in the northern part of Japan, has defined itself as a university with strong enrollment management that is carried out at the IR office. The enrollment management covers not only the enrollment issues but also student learning support, carrier support with services extending after graduation to alumni support.

The circumstances are more severe for the private universities than the national universities. With less prestige than the national universities, the shrinking population and economic downturn are hitting the private universities even more. Until the 1980s, the student population was growing, and even the private universities, which are self-governed private entities, could grow every year without careful management. However, after the economic bubble collapsed at the beginning of the 1990s, and the shrinking student population at the same period, the private 
universities are facing the need to be innovative to survive. At present, the big private universities in urban areas are still welcoming growth in student numbers while their peers in rural areas are almost forced to shut down the universities. However, this will not last long.

To summarize, we are approaching an era where rigorous university management is needed, which will require the support of IR offices in due course.

\subsection{How should IR offices in Japanese universities evolve?}

The management structure of Japanese universities can be said to be in a transition phase. Until recently, both the national and private universities had no great need to manage their university proactively. Hence, the organizational structure for regular university management, both for the administration and the supporting units, are existent only in a weak form. As we approach tough times with shrinking student population and economic recession, an organization for regular university management will settle in.

Establishing IR offices can be regarded as the first step. However, since decision-making takes place at administration-level, it is necessary for administrators to understand the necessity and critical point of university management. There are certain key factors that should be taken care of at regular university management. One simple example would be KPIs. Since university management in Japanese universities is still at infancy level, these cannot be given top-down, but have to be worked out through trial and error. It is favorable that university administration and IR offices work through this process side by side. This will be a good exercise for their capacity building.

There is a good chance that both the administration and IR office build their capacity in university management. On the other hand, IR offices are on very weak grounds. Since these are units newly established, the offices are not well known within the university including even among the administrators. There are several cases where IR staff members were laid off upon the expiration of their term, or after a change in the president and the according administration before they could build their capacity and provide meaningful work. In a worse scenario, the IR offices are even shut down. Since the administration changes every four to six years in each university, it is difficult to assume that they have gained sufficient capacity to be transferred to the next administration. Many of the IR staff worry that IR offices will not gain ground in Japanese universities.

For regular university management to be accustomed in Japanese universities, it is essential that the university administration as well as the IR offices accumulate their expertise and build their capacity. It is inevitable and beneficial for the university that the administration changes over time. Instead, the IR offices should be set for a longer period on firm grounds to act as an institutional memory for the administration. Providing more stable positions for IR staff at the IR offices is fundamental for this to happen. In addition, IR staff will need to show their expertise as IR professionals. It is recommended that IR staff organize themselves to exchange information and define the standard knowledge and skills for IR professionals. This should be shared among IR staff through training courses and qualifications. An association, such as the Association for Institutional Research (AIR) in the US, will be beneficial to assure quality. As the higher education system and the according university management differ profoundly among different countries, an IR Association for Japan will be needed. 


\section{Acknowledgement}

This work was supported by JSPS KAKENHI Grant Number 22653097, “Academic Management in Top Research Universities."

\section{References}

[1] M. Trow, "The Expansion and Transformation of Higher Education," International Review of Education, Vol 18, Issue 1, pp. 61-84, December 1972.

[2] M. W. Peterson, "The Role of Institutional Research: From Improvement to Redesign," New Directions for Institutional Research, No. 104, pp. 83-103, Winter 1999.

[3] Kawai-jyuku, "The Enrollment Quota of Private Universities Improving to 43\%," Kei-Net, August 2015; http://www.keinet.ne.jp/topics/15/20150810.pdf.

[4] Central Council for Education, "Towards Establishing Bachelor's Degree Program," December 2008; Chuou Kyouiku Shingikai, "Gakushi-katei-kyouiku no Kouchiku-ni Mukete."

[5] Committee Concerning the Management Expenses Grants for National University Corporations for the Third Term Mid-term Objectives "Report on the Management Expenses Grants for National University Corporations for the Third Term Mid-term Objectives," June 2015; "Dai-san-ki Chuki-Mokuhyou-Kikan niokeru Kokuritsu-Daigaku-Houjin Uneihi-Koufukin no Arikata ni tsuite Shingi-matome," http://www.mext.go.jp/b_menu/shingi/chousa/koutou/062/gaiyou/1358931.htm.

[6] J. F. Volkwein, “The Four Faces of Institutional Research,” New Directions for Institutional Research, No. 104, pp. 9-19, Winter 1999.

[7] P. L. Dressel, “The Shaping of Institutional Research and Planning," Research in Higher Education, Vol. 14, No. 3, pp. 229-258, 1981.

[8] P. T. Terenzini, "On the Nature of Institutional Research and the Knowledge and Skills It Requires,” New Directions for Institutional Research, No. 104, pp. 21-29, Winter 1999.

[9] S. W. Thorpe, "The Mission of Institutional Research," 26th Conference of the North East Association for Institutional Research, pp. 211-218, 1999.

[10] P. Maassen, "Institutional research and organizational adaptation," 8th European AIR Forum, 1986.

[11] A. M. Delaney, "The role of institutional research in higher education: Enabling researchers to meet new challengers," Research in Higher Education, No. 38, pp. 1-16, 1997.

[12] R. L. Swing, "Institutional Researchers as Change Agents," New Directions for Institutional Research, No. 143, pp. 5-16, Fall 2009. 
[13] C. Leimer and D. G. Terkla, "Laying the foundation: Institutional Research Office Organization, Staffing, and Career Development," New Directions for Institutional Research, No. 143, pp. 43-58, Fall 2009.

[14] J. L. Saupe, "The Function of Institutional Research 2nd Edition," Association for Institutional Research, 1990.

[15] D. M. Norris, "Triage and the Art of Institutional Research", in R. R. Perry and J. Y. Reid (eds.), Institutional Research Issues and Applications 1978-1983. AIR Professional File 1-16, Tallahassee, Fla.: Association for Institutional Research, 1983.

[16] F. D. Billups and L. A. DeLucia, "Integrating Institutional Research into the Organization," New Directions for Institutional Research, No. 66, pp. 93-102, Summer 1990.

[17] A. M. Delaney, “Institutional Researchers' Expanding Roles: Policy, Planning, Program Evaluation, Assessment, and New Research Methodologies," New Directions for Institutional Research, No. 143, pp. 29-41, Fall 2009.

[18] The University of Tokyo, "Report on the Institutional Research in Japan," Contract Report of the University Reform Promotion by MEXT, F.Y. 2012-13, March 2014; "Daigaku niokeru IR no Genjou to Arikata ni-kansuru Chousa-kenkyu Houkokusho," http://www.mext.go.jp/a_menu/koutou/itaku/1347631.htm.

[19] S. Okada and K. Oki, "Flash report: Survey on Gathering and Analyzing Information within University for Function Improvement Purpose," unpublished, March 2009.

[20] T. Kominato and T. Nakai, "Institutional Research at National University Corporations: The Cases of Nagoya University, Ehime Univerisity, and Kyushu University," Research on Academic Degrees and University Evaluation, No. 5, pp. 19-34, 2007.

[21] A. L. Taylor, "Options for Location in the Organizational Structure," New Directions for Institutional Research, No. 66, pp. 27-34, Summer 1990.

[22] J. B. Presley, "Putting the Building Blocks into Place for Effective Institutional Research," New Directions for Institutional Research, No. 66, pp. 103-106, Summer 1990.

[23] S. Lindquist, "A Profile of Institutional Researchers from AIR National Membership Surveys", New Directions for Institutional Research, No. 104, pp. 41-50, Winter 1999.

[24] J. F. Volkwein, "The Foundations and Evolution of Institutional Research," New Directions for Institutional Research, No. 141, pp. 5-20, Spring 2008.

[25] M. Fujiwara, S. Chikamori, A. Asano, and N. Yoshii, "Development of Institutional Research (IR) to Support Policy Formulation in the Educational Field: Definition, Organizational Structure, and Processes of Institutional Research in the Educational Field at Ritsumeikan University," University Administration Studies, No. 4, pp. 17-31, 2009. 